\title{
Clinical application of anti-Müllerian hormone as a predictor of controlled ovarian hyperstimulation outcome
}

\author{
Jae Eun Lee ${ }^{1 *}$, Jung Ryeol Lee ${ }^{1,2 *}$, Byung Chul Jee ${ }^{1,2}$, Chang Suk Suh ${ }^{1,2}$, Ki Chul Kim³, Won Don Lee ${ }^{4}$, Seok Hyun Kim ${ }^{1}$ \\ 'Department of Obstetrics and Gynecology, Seoul National University College of Medicine, Seoul; ${ }^{2}$ Department of Obstetrics and Gynecology, Seoul \\ National University Bundang Hospital, Seoul National University College of Medicine, Seongnam; ${ }^{3}$ Hamchoon Women's Clinics, Seoul; ${ }^{4}$ Maria Infertility \\ Hospital, Seoul, Korea
}

Objective: In 2009 anti-Müllerian hormone (AMH) assay was approved for clinical use in Korea. This study was performed to determine the reference values of AMH for predicting ovarian response to controlled ovarian hyperstimulation $(\mathrm{COH})$ using the clinical assay data.

Methods: One hundred sixty-two women who underwent $\mathrm{COH}$ cycles were included in this study. We collected data on age, basal AMH and FSH levels, total dose of gonadotropins, stimulation duration, and numbers of oocytes retrieved and fertilized. Blood samples were obtained on cycle day 3 before gonadotropin administration started. Serum AMH levels were measured at a centralized clinical laboratory center. The correlation between the $\mathrm{AMH}$ level and $\mathrm{COH}$ outcomes and cut-off values for poor and high response after $\mathrm{COH}$ was analyzed.

Results: Concentration of AMH was significantly correlated with the number of oocytes retrieved (OPU; $r=0.700, p<0.001$ ). The mean $\pm \mathrm{SE}$ serum $A M H$ levels for poor (OPU $\leq 3)$, normal $(4 \leq \mathrm{OPU} \leq 19)$, and high (OPU $\geq 20)$ response were $0.94 \pm 0.15 \mathrm{ng} / \mathrm{mL}, 2.79 \pm 0.21 \mathrm{ng} / \mathrm{mL}$, and $6.94 \pm 0.90 \mathrm{ng} / \mathrm{mL}$, respectively. The cut-off level, sensitivity and specificity for poor and high response were $1.08 \mathrm{ng} / \mathrm{mL}, 85.8 \%$, and $78.6 \%$; and $3.57 \mathrm{ng} / \mathrm{mL}, 94.4 \%$, and $83.3 \%$, respectively.

Conclusion: Our data present clinical reference values of the serum AMH level for ovarian response in Korean women. The serum AMH level could be a clinically useful predictor of ovarian response to $\mathrm{COH}$.

Keywords: Anti-Müllerian hormone; Ovarian response; Outcome predictor; Controlled ovarian hyperstimulation

\section{Introduction}

Recently, anti-Müllerian hormone (AMH) has been suggested as an ovarian reserve marker and predictor of ovarian response to controlled ovarian hyperstimulation $(\mathrm{COH})$ in assisted reproduction cycles $[1,2]$. Several investigators have demonstrated that serum AMH concentrations during the early follicular phase of the menstrual cy-

Received: Aug 15, 2012 · Revised: Oct 29, 2012 - Accepted: Nov 8, 2012 Corresponding author: Seok Hyun Kim

Department of Obstetrics and Gynecology, Seoul National University College of Medicine, 101 Daehak-ro, Jongno-gu, Seoul 110-744, Korea

Tel: +82-2-2072-3773 Fax:+82-2-762-3599 E-mail: seokhyun@snu.ac.kr

*The first two authors contributed equally to this work.

This is an Open Access article distributed under the terms of the Creative Commons Attribution Non-Commercial License (http://creativecommons.org/licenses/by-nc/3.0/) which permits unrestricted non-commercial use, distribution, and reproduction in any medium, provided the original work is properly cited. cle decrease consistently with age in women, and the change starts at younger ages than does that of conventional markers such as FSH $[3,4]$. In addition, it has been shown that the basal AMH level is correlated with antral follicle count (AFC), $E_{2}$ level on $\mathrm{hCG}$ day, number of mature follicles on $\mathrm{hCG}$ day, and the number of oocytes retrieved after $\mathrm{COH}[1,5,6]$.

Although numerous studies have confirmed the usefulness of AMH as an outcome predictor, there have been no confirmed reference values of serum AMH level for prediction of ovarian response. Moreover, most studies have shown data from experimental laboratory measurements of AMH levels. Thus, the practical use of AMH was hindered by the lack of clinical data and reference values. In Korea, the clinical measurement of the serum AMH level was approved by the government and has been performed clinically in large commercial laboratory centers since 2009. In the present study, we retrospec- 
tively analyzed the clinical assay data and the relationship between serum $\mathrm{AMH}$ levels and ovarian response to $\mathrm{COH}$ and determined the cut-off value of AMH levels for predicting poor, normal, and high responders.

\section{Methods}

\section{Patients}

We collected data from a total of 162 women who had undergone $\mathrm{COH}$ cycles with $\mathrm{GnRH}$ agonist $(\mathrm{n}=99)$ or $\mathrm{GnRH}$ antagonist $(\mathrm{n}=63)$ protocols. The age of the 162 women ranged from 20 to 46 years and the mean age was 35 years. The study was approved by the Institutional Review Board of Seoul National University Bundang Hospital.

\section{2. $\mathrm{COH}$ protocols}

For the GnRH agonist long protocol, GnRH agonist, $0.1 \mathrm{mg} /$ day of triptorelin (Decapeptyl, Ferring, Malmo, Sweden) was started in the mid-luteal phase of the previous cycle. After pituitary down-regulation, the triptorelin dose was reduced to $0.05 \mathrm{mg} / \mathrm{day}$, and gonadotropins (recombinant FSH, Gonal-F, Serono, Geneva, Switzerland; or urinary hMG, IVF-M, LG Life Science, Seoul, Korea) were added until the leading follicle reached a mean diameter of $18 \mathrm{~mm}$ or two follicles or more reached a diameter of $17 \mathrm{~mm}$. For the GnRH antagonist protocol, gonadotropins were started on the second or third menstrual cycle day without previous oral contraceptive pretreatment. $\mathrm{GnRH}$ antagonist, $0.25 \mathrm{mg}$ of cetrorelix (Cetrotide, Serono) was added daily, starting when the leading follicle reached a diameter of 14 $\mathrm{mm}$ until the leading follicle reached a mean diameter of $18 \mathrm{~mm}$ or two follicles or more reached a diameter of $17 \mathrm{~mm}$. For both protocols, $250 \mu \mathrm{g}$ of recombinant hCG (Ovidrel, Serono) was administered 36 hours before transvaginal oocyte retrieval. Up to four embryos were transferred 2 or 3 days after oocyte retrieval. The luteal phase was supported with $50 \mathrm{mg}$ of progesterone in oil (Genefer progesterone, Genefer, Seoul, Korea) or $8 \%$ progesterone gel (Crinone, Serono) daily, initially for 14 days starting on the day of oocyte retrieval and continuing for another 6 to 8 weeks in cases where a pregnancy was achieved.

\section{AMH measurement}

The serum AMH level for each woman was measured with blood samples obtained on cycle day 2 or 3 before gonadotropin stimulation started. Serum samples were transferred to a commercial laboratory center and $\mathrm{AMH}$ was measured using enzyme-linked immunosorbent assay (ELISA, Beckman Coulter Immunotech, Marseille, France). The intra- and interassay coefficients of variation were $12.3 \%$ and $14.2 \%$, respectively.

\section{Data analysis}

We collected the data on age, basal AMH and FSH levels, total dose of gonadotropins, stimulation duration, and numbers of oocytes retrieved and fertilized. The main outcome measures were serum AMH level and number of retrieved oocytes. A poor ovarian response was defined as a fewer than four oocytes and normal response as a collection of four to nineteen oocytes. Patients with more than 19 oocytes retrieved were defined as high responders. Clinical pregnancy was defined by the presence of an intrauterine gestational sac with pulsating fetal heart beats 4-5 weeks after oocyte retrieval.

Statistical analysis was performed using an analysis of variance test for continuous variables and $x^{2}$-test for categorical variables. Correlations between $\mathrm{AMH}$ and $\mathrm{COH}$ outcomes were determined by bivariate correlation analysis and are expressed as Pearson's correlation coefficients. Receiver operating characteristic curve analysis was performed and the cut-off value, sensitivity and specificity for poor and high response in AMH levels were evaluated. The SPSS ver. 12.0 (SPSS Inc., Chicago, IL, USA) was used for statistical analysis and the results were considered statistically significant at $p$-values of $<0.05$.

\section{Results}

The serum AMH levels correlated negatively with age $(r=-0.447$, $p<0.001)$ and positively with the number of oocytes retrieved $(r=$ $0.700, p<0.001$ ) (Figure 1). Table 1 shows the demographic and outcome parameters of the poor, normal, and high response groups. A total of 42 patients had a poor response ( $\leq 3$ oocytes) to gonadotropin stimulation, while 18 had a high response ( $\geq 20$ oocytes). The 102 patients had shown normal responses (4 to 19 oocytes). Basal FSH levels and stimulation days were not statistically different. However, the age, basal AMH level, total dose of gonadotropins, number of retrieved and fertilized oocytes, and clinical pregnancy rate were significantly different between the groups. The mean $( \pm \mathrm{SE})$ serum AMH level for poor, normal, and high responses were $0.94 \pm 0.15 \mathrm{ng} /$ $\mathrm{mL}, 2.79 \pm 0.21 \mathrm{ng} / \mathrm{mL}$, and $6.94 \pm 0.90 \mathrm{ng} / \mathrm{mL}$, respectively (Table 1).

Patients were further subdivided into four groups using the 25th, 50th, and 75 th percentiles according to AMH values $(0.85 \mathrm{ng} / \mathrm{mL}, 1.89$ $\mathrm{ng} / \mathrm{mL}$, and $3.64 \mathrm{ng} / \mathrm{mL}$, respectively). Except for stimulation duration, the outcome parameters of $\mathrm{COH}$ were also significantly different according to the quartile AMH levels (Table 2).

The AMH levels performed well in prediction of poor and high response after $\mathrm{COH}$ (AUC 0.869, $p<0.001$; AUC $0.912, p<0.001$ for poor and high response, respectively). The cut-off level, sensitivity, and specificity for poor and high response were $1.08 \mathrm{ng} / \mathrm{mL}, 85.8 \%$, and 78.6\%; and $3.57 \mathrm{ng} / \mathrm{mL}, 94.4 \%$, and 83.3\%, respectively (Table 3, Figure 2). 

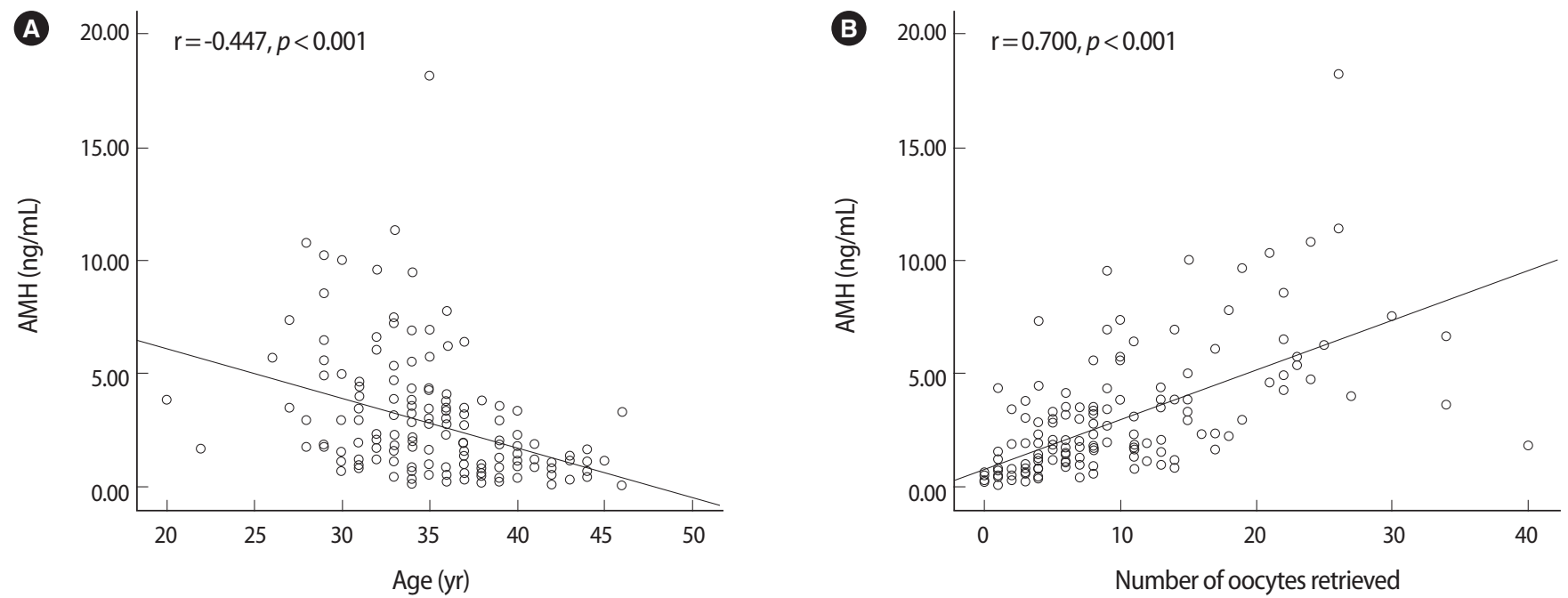

Figure 1. Correlation of age (A) and number of oocytes retrieved (B) with anti-Müllerian hormone (AMH) level.

Table 1. Demographic and outcome parameters according to ovarian response

\begin{tabular}{|c|c|c|c|c|}
\hline & $\begin{array}{l}\text { Poor responders } \\
(\mathrm{OPU} \leq 3, n=42)\end{array}$ & $\begin{array}{l}\text { Normal responders } \\
(4 \leq \mathrm{OPU} \leq 19, \mathrm{n}=102)\end{array}$ & $\begin{array}{l}\text { High responders } \\
(\mathrm{OPU} \geq 20, \mathrm{n}=18)\end{array}$ & $p$-value \\
\hline Age (yr) & $37.7 \pm 4.2^{\mathrm{a}}$ & $34.9 \pm 4.5^{b}$ & $31.7 \pm 2.8^{c}$ & $<0.001$ \\
\hline Basal AMH (ng/mL) & $0.94 \pm 0.15^{\mathrm{a}}$ & $2.79 \pm 0.21^{\mathrm{b}}$ & $6.94 \pm 0.90^{c}$ & $<0.001$ \\
\hline Basal FSH (mlU/mL) & $9.9 \pm 3.9$ & $8.7 \pm 7.7$ & $7.1 \pm 1.6$ & 0.578 \\
\hline Total dose of gonadotropins (IU) & $2,328.8 \pm 1,138.1^{a}$ & $2,829.5 \pm 909.4^{b}$ & $2,348.4 \pm 473.3^{\mathrm{a}}$ & 0.009 \\
\hline Stimulation days & $9.9 \pm 3.0^{\mathrm{a}}$ & $9.7 \pm 1.7^{a, b}$ & $8.3 \pm 1.5^{b}$ & 0.089 \\
\hline No. of oocytes retrieved & $1.8 \pm 1.1^{\mathrm{a}}$ & $8.9 \pm 4.1^{b}$ & $25.9 \pm 5.3^{c}$ & $<0.001$ \\
\hline No. of fertilized oocytes & $1.3 \pm 1.0^{\mathrm{a}}$ & $5.1 \pm 2.5^{b}$ & $13.4 \pm 2.3^{c}$ & $<0.001$ \\
\hline Clinical pregnancy rate (\%) & $7.1^{\mathrm{a}}$ & $24.5^{b}$ & $44.4^{c}$ & $<0.001$ \\
\hline
\end{tabular}

Values are presented as mean \pm SD except $\mathrm{AMH}$ (mean $\pm \mathrm{SE}$ ).

$\mathrm{OPU}$, number of oocytes retrieved; $\mathrm{AMH}$, anti-Müllerian hormone.

$\mathrm{a}, \mathrm{b}, \mathrm{c}$ ifferent letters indicate significant differences.

Table 2. Demographic and outcome parameters according to quartile AMH level

\begin{tabular}{|c|c|c|c|c|c|}
\hline & $\begin{array}{c}\mathrm{AMH} \leq 0.84 \mathrm{ng} / \mathrm{mL} \\
(\mathrm{n}=40)\end{array}$ & $\begin{array}{c}0.85 \leq \mathrm{AMH} \leq 1.88 \mathrm{ng} / \mathrm{mL} \\
(\mathrm{n}=42)\end{array}$ & $\begin{array}{c}1.89 \leq \mathrm{AMH} \\
\quad \leq 3.63 \mathrm{ng} / \mathrm{mL} \\
(\mathrm{n}=40)\end{array}$ & $\begin{array}{c}3.64 \mathrm{ng} / \mathrm{mL} \leq \mathrm{AMH} \\
(\mathrm{n}=40)\end{array}$ & $p$-value \\
\hline Age (yr) & $37.8 \pm 4.0^{\mathrm{a}}$ & $35.9 \pm 5.3^{b}$ & $35.1 \pm 3.5^{b}$ & $32.2 \pm 3.5^{c}$ & $<0.001$ \\
\hline Basal AMH (ng/mL) & $0.49 \pm 0.22^{\mathrm{a}}$ & $1.34 \pm 0.33^{b}$ & $2.83 \pm 0.55^{c}$ & $6.49 \pm 2.86^{d}$ & $<0.001$ \\
\hline Basal FSH (mlU/mL) & $12.7 \pm 10.2^{\mathrm{a}}$ & $6.8 \pm 3.2^{b}$ & $7.5 \pm 2.3^{b}$ & $7.4 \pm 2.7^{b}$ & 0.003 \\
\hline Total dose of gonadotropins (IU) & $2,294.2 \pm 1,111.5^{\mathrm{a}}$ & $3,090.0 \pm 980.7^{b}$ & $2,915.3 \pm 637.5^{\mathrm{b}}$ & $2,247.9 \pm 763.9^{a}$ & $<0.001$ \\
\hline Stimulation days & $9.6 \pm 2.9$ & $10.1 \pm 2.4$ & $9.6 \pm 1.3$ & $8.8 \pm 1.7$ & 0.354 \\
\hline No. of oocytes retrieved & $2.9 \pm 2.9^{\mathrm{a}}$ & $7.3 \pm 6.4^{b}$ & $9.5 \pm 5.8^{b}$ & $16.2 \pm 8.1^{c}$ & $<0.001$ \\
\hline No. of fertilized oocytes & $1.5 \pm 1.2^{\mathrm{a}}$ & $5.1 \pm 3.0^{b}$ & $4.8 \pm 1.6^{b}$ & $8.3 \pm 4.8^{c}$ & $<0.001$ \\
\hline
\end{tabular}

Values are presented as mean \pm SD.

$\mathrm{AMH}$, anti-Müllerian hormone.

$\mathrm{a}, \mathrm{b}, \mathrm{c}, \mathrm{d}$ Different letters indicate significant differences.

\section{Discussion}

In this study, we confirmed the usefulness of AMH as a predictor of ovarian response to $\mathrm{COH}$. The serum AMH level was significantly dif- ferent according to the ovarian response to $\mathrm{COH}$ in contrast to $\mathrm{FSH}$ which showed no difference among the poor, normal, and high response groups. In addition, we determined the cut-off values of AMH levels for poor and high ovarian responders among Korean women 
Table 3. Results of the receiver operating characteristics curve analysis of serum AMH concentration discriminating for controlled ovarian stimulation outcomes

\begin{tabular}{lccccc}
\hline Outcomes & Cut-off $(\mathrm{ng} / \mathrm{mL})$ & Sensitivity $(\%)$ & Specificity $(\%)$ & AUC $(95 \% \mathrm{Cl})$ & $p$-value \\
\hline Poor response $(\mathrm{OPU} \leq 3)$ & 1.08 & 85.80 & 78.60 & $0.869(0.804-0.935)$ & $<0.001$ \\
High response $(\mathrm{OPU} \geq 20)$ & 3.57 & 94.40 & 83.30 & $0.912(0.855-0.970)$ & $<0.001$ \\
\hline
\end{tabular}

$\mathrm{AMH}$, anti-Müllerian hormone; $\mathrm{AUC}$, area under the curve; $\mathrm{Cl}$, confidence interval; $\mathrm{OPU}$, number of oocytes retrieved.
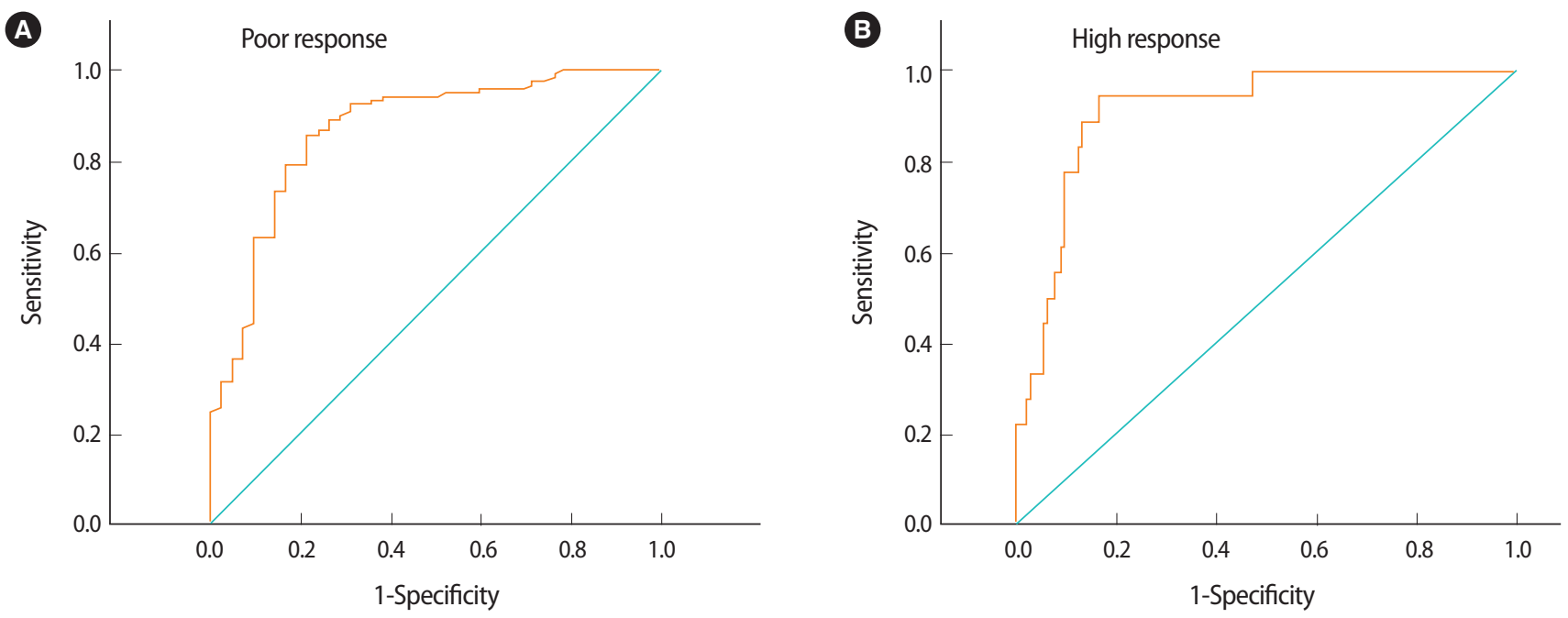

Figure 2. Receiver operating curve analysis showing the relation between anti-Müllerian hormone (AMH) and number of oocytes retrieved in (A) poor responders ( $\leq 3$ oocytes) and (B) high responders ( $\geq 20$ oocytes).

with clinical assay data. The cut-off levels we presented in this study show good concordance with the values presented in other recent studies [7-14]. This means that the cut-off values measured by clinical assay correlate well with the values measured in each research laboratory.

Currently, the $\mathrm{AMH}$ value has been suggested as an ovarian reserve marker $[1,2,5,9]$. Before the studies of AMH were published, other conventional methods had been developed for predicting ovarian reserve such as early follicular $\mathrm{FSH}, \mathrm{E}_{2}$, and the clomiphene challenge test. However, these traditional assessments have low sensitivity in the early stages of reduced ovarian reserve [15]. Several authors have reported that $A F C$ yields the best prognostic information with regard to the occurrence of poor response in IVF $[5,16]$. However, AFC has the limitation of high inter-observer variability due to the duration of the vaginal ultrasound examination, observers' experiences and, notably, expected ovarian reserve due to the patient's age [9]. Recently, $\mathrm{AMH}$ was also found to have predictive performance comparable with that of AFC $[5,17]$. There are advantages to the use of AMH over other markers since there are relatively minimal intra- and inter-cycle variations in serum levels. Therefore AMH can be measured throughout the cycle in contrast to the other markers, which would only be checked during the early follicle phase $[5,18,19]$. Moreover, AMH levels can be obtained by objective measurements performed in a well- controlled laboratory and thus are free of inter-observer variability, which is shown in AFC measurements [20].

To date, many studies have reported various cut-off levels of $\mathrm{AMH}$, but there is no consensus on cut-off values for predicting poor or high response to $\mathrm{COH}$. This discrepancy may be due to the different criteria for poor responses, different study populations, and different sampling days. Using different types of ELISA kits, the Immunotech Beckman Coulter kit or the Diagnostic Systems Laboratories kit, for measuring AMH levels was has also been suggested as one of the causes. Those two types of kits are commercially available and used in almost all published studies. Several studies have compared the two kits, but the results have been inconsistent. Fréour et al. [21] and Bersinger et al. [22] reported that there were discordances between the AMH levels measured by the two kits and that they were due to the lack of an international standard and residual matrix effects. However, recent studies have shown that the AMH levels measured by the two kits are not different and concluded that similar reference values could be used with both kits [23,24]. La Marca et al. [25] suggested that the methological problems that were observed in earlier studies could have been solved by the manufacturers. Therefore, it was concluded that, at least in recent studies, using different types of kits is not the cause of discrepancies in cut-off values of AMH. Indeed, the cut-off values of $\mathrm{AMH}$ for poor or high response to $\mathrm{COH}$ reported 
in recent studies have been within a small range. The currently reported cut-off values were 0.99 to $1.40 \mathrm{ng} / \mathrm{mL}$ for poor responders $[7-9,14,21,26]$ and $3.36-3.55 \mathrm{ng} / \mathrm{mL}$ for high responders $[11,13,14]$. In our study, the cut-off values of AMH were $1.08 \mathrm{ng} / \mathrm{mL}$ and $3.57 \mathrm{ng} /$ $\mathrm{mL}$, respectively, which are similar with the results of recent studies. This means that the cut-off values measured in the clinical assays correlate well with the values measured previously in each research laboratory.

In the present study, women who underwent $\mathrm{GnRH}$ agonist or GnRH antagonist protocol were included, but $\mathrm{COH}$ outcomes such as the number of oocytes retrieved, number of fertilized oocytes, and clinical pregnancy rate were not significantly different (data not shown). This result is in line with that of a previous study that showed that serum and follicular fluid AMH levels and $\mathrm{COH}$ outcomes did not differ between the two protocols [6].

The pretreatment prediction of ovarian reserve in IVF patients allows for appropriate counseling and modification of an individual's treatment protocol, thereby maximizing their chances of a successful outcome [27-29]. We believe that ovarian reserve testing using AMH is likely to become a routine practice in the evaluation of infertile couples $[5,28]$. The augmentation of the starting dose of gonadotropins can be attempted for poor responders. On the other hand, a low gonadotropin dose can be used to reduce the incidence of OHSS for patients with high serum AMH levels [30]. The clinical usefulness of AMH has been confirmed by numerous studies using research data. In this study, we also confirmed the clinical value of AMH by clinically measured data. Therefore, the clinical measurement of $\mathrm{AMH}$ is a feasible method for ovarian reserve testing and the measurement has a good value for the government approval of clinical assay as approved by the Korean government in 2009. In conclusion, the cut-off values measured in clinical assay correlate well with the previously reported values measured in research laboratories. Our data present clinical reference values of serum AMH level for ovarian response and these cut-off levels could be used practically to predict poor or high response to $\mathrm{COH}$. The government approval of $\mathrm{AMH}$ measurement helps to make the AMH used more widely in clinical situations.

\section{Conflict of interest}

No potential conflict of interest relevant to this article was reported.

\section{References}

1. Seifer DB, MacLaughlin DT, Christian BP, Feng B, Shelden RM. Early follicular serum mullerian-inhibiting substance levels are associated with ovarian response during assisted reproductive technology cycles. Fertil Steril 2002;77:468-71.
2. Hazout $A$, Bouchard $P$, Seifer DB, Aussage $P$, Junca AM, CohenBacrie P. Serum antimullerian hormone/mullerian-inhibiting substance appears to be a more discriminatory marker of assisted reproductive technology outcome than follicle-stimulating hormone, inhibin B, or estradiol. Fertil Steril 2004;82:1323-9.

3. de Vet A, Laven JS, de Jong FH, Themmen AP, Fauser BC. Antimullerian hormone serum levels: a putative marker for ovarian aging. Fertil Steril 2002;77:357-62.

4. Shin SY, Lee JR, Noh GW, Kim HJ, Kang WJ, Kim SH, et al. Analysis of serum levels of anti-Mullerian hormone, inhibin B, insulin-like growth factor-l, insulin-like growth factor binding protein-3, and follicle-stimulating hormone with respect to age and menopausal status. J Korean Med Sci 2008;23:104-10.

5. van Rooij IA, Broekmans FJ, te Velde ER, Fauser BC, Bancsi LF, de Jong $\mathrm{FH}$, et al. Serum anti-Mullerian hormone levels: a novel measure of ovarian reserve. Hum Reprod 2002;17:3065-71.

6. Lee JR, Kim SH, Kim SM, Jee BC, Ku SY, Suh CS, et al. Anti-Mullerian hormone dynamics during controlled ovarian hyperstimulation and optimal timing of measurement for outcome prediction. Hum Reprod 2010;25:2597-604.

7. Smeenk JM, Sweep FC, Zielhuis GA, Kremer JA, Thomas CM, Braat $\mathrm{DD}$. Antimullerian hormone predicts ovarian responsiveness, but not embryo quality or pregnancy, after in vitro fertilization or intracyoplasmic sperm injection. Fertil Steril 2007;87:223-6.

8. Mcllveen M, Skull JD, Ledger WL. Evaluation of the utility of multiple endocrine and ultrasound measures of ovarian reserve in the prediction of cycle cancellation in a high-risk IVF population. Hum Reprod 2007;22:778-85.

9. Gnoth C, Schuring AN, Friol K, Tigges J, Mallmann P, Godehardt E. Relevance of anti-Mullerian hormone measurement in a routine IVF program. Hum Reprod 2008;23:1359-65.

10. Jayaprakasan K, Campbell B, Hopkisson J, Johnson I, Raine-Fenning N. A prospective, comparative analysis of anti-Mullerian hormone, inhibin-B, and three-dimensional ultrasound determinants of ovarian reserve in the prediction of poor response to controlled ovarian stimulation. Fertil Steril 2010;93:855-64.

11. Lee $\mathrm{TH}$, Liu CH, Huang CC, Wu YL, Shih YT, Ho HN, et al. Serum anti-Mullerian hormone and estradiol levels as predictors of ovarian hyperstimulation syndrome in assisted reproduction technology cycles. Hum Reprod 2008;23:160-7.

12. Nelson SM, Yates RW, Lyall H, Jamieson M, Traynor I, Gaudoin M, et al. Anti-Mullerian hormone-based approach to controlled ovarian stimulation for assisted conception. Hum Reprod 2009;24: 867-75.

13. Nardo LG, Gelbaya TA, Wilkinson H, Roberts SA, Yates A, Pemberton $\mathrm{P}$, et al. Circulating basal anti-Mullerian hormone levels as predictor of ovarian response in women undergoing ovarian 
stimulation for in vitro fertilization. Fertil Steril 2009;92:1586-93.

14. Choi MH, Yoo JH, Kim HO, Cha SH, Park CW, Yang KM, et al. Serum anti-Mullerian hormone levels as a predictor of the ovarian response and IVF outcomes. Clin Exp Reprod Med 2011;38:153-8.

15. van Rooij IA, Broekmans FJ, Hunault CC, Scheffer GJ, Eijkemans $\mathrm{MJ}$, de Jong $\mathrm{FH}$, et al. Use of ovarian reserve tests for the prediction of ongoing pregnancy in couples with unexplained or mild male infertility. Reprod Biomed Online 2006;12:182-90.

16. Bancsi LF, Broekmans FJ, Eijkemans MJ, de Jong FH, Habbema $J D$, te Velde ER. Predictors of poor ovarian response in in vitro fertilization: a prospective study comparing basal markers of ovarian reserve. Fertil Steril 2002;77:328-36.

17. Eldar-Geva T, Ben-Chetrit A, Spitz IM, Rabinowitz R, Markowitz E, Mimoni T, et al. Dynamic assays of inhibin B, anti-Mullerian hormone and estradiol following FSH stimulation and ovarian ultrasonography as predictors of IVF outcome. Hum Reprod 2005;20: 3178-83.

18. La Marca A, Giulini S, Tirelli A, Bertucci E, Marsella T, Xella S, et al. Anti-Mullerian hormone measurement on any day of the menstrual cycle strongly predicts ovarian response in assisted reproductive technology. Hum Reprod 2007;22:766-71.

19. Hehenkamp WJ, Looman CW, Themmen AP, de Jong FH, Te Velde ER, Broekmans FJ. Anti-Mullerian hormone levels in the spontaneous menstrual cycle do not show substantial fluctuation. J Clin Endocrinol Metab 2006;91:4057-63.

20. Fiçicioglu C, Kutlu T, Baglam E, Bakacak Z. Early follicular antimullerian hormone as an indicator of ovarian reserve. Fertil Steril 2006; 85:592-6.

21. Fréour T, Mirallié S, Bach-Ngohou K, Denis M, Barrière P, Masson D. Measurement of serum anti-Mullerian hormone by Beckman Coulter ELISA and DSL ELISA: comparison and relevance in assisted reproduction technology (ART). Clin Chim Acta 2007;375:
162-4.

22. Bersinger NA, Wunder D, Birkhäuser MH, Guibourdenche J. Measurement of anti-mullerian hormone by Beckman Coulter ELISA and DSL ELISA in assisted reproduction: differences between serum and follicular fluid. Clin Chim Acta 2007;384:174-5.

23. Streuli I, Fraisse T, Chapron C, Bijaoui G, Bischof P, de Ziegler D. Clinical uses of anti-Mullerian hormone assays: pitfalls and promises. Fertil Steril 2009;91:226-30.

24. Lee JR, Kim SH, Jee BC, Suh CS, Kim KC, Moon SY. Antimullerian hormone as a predictor of controlled ovarian hyperstimulation outcome: comparison of two commercial immunoassay kits. Fertil Steril 2011;95:2602-4.

25. La Marca A, Sighinolfi G, Radi D, Argento C, Baraldi E, Artenisio $A C$, et al. Anti-Mullerian hormone (AMH) as a predictive marker in assisted reproductive technology (ART). Hum Reprod Update 2010;16:113-30.

26. Kwee J, Schats R, McDonnell J, Themmen A, de Jong F, Lambalk C. Evaluation of anti-Mullerian hormone as a test for the prediction of ovarian reserve. Fertil Steril 2008;90:737-43.

27. Muttukrishna S, Suharjono H, McGarrigle H, Sathanandan M. Inhibin $B$ and anti-Mullerian hormone: markers of ovarian response in IVF/ICSI patients? BJOG 2004;111:1248-53.

28. Tremellen KP, Kolo M, Gilmore A, Lekamge DN. Anti-mullerian hormone as a marker of ovarian reserve. Aust N Z J Obstet Gynaecol 2005;45:20-4.

29. Arslan M, Bocca S, Mirkin S, Barroso G, Stadtmauer L, Oehninger S. Controlled ovarian hyperstimulation protocols for in vitro fertilization: two decades of experience after the birth of Elizabeth Carr. Fertil Steril 2005;84:555-69.

30. Al-Inany HG, Abou-Setta AM, Aboulghar M. Gonadotrophin-releasing hormone antagonists for assisted conception. Cochrane Database Syst Rev 2006;(3):CD001750. 